\title{
Meteorological parameters impact on spatio-temporal dynamics of VOCs after CNG implementation in transport sector in Delhi
}

\author{
Deepak Singh $^{\mathrm{a} *}$, Amit Kumar ${ }^{\mathrm{b}}$, Braj Bihari Singh ${ }^{\mathrm{c}}$, Vinod Kumar Jain ${ }^{\mathrm{a}}$ \\ ${ }^{a}$ Jawaharlal Nehru University, New Delhi, India \\ ${ }^{b}$ National Physical Laboratory, New Delhi, India \\ ${ }^{c}$ University of Delhi, New Delhi, India
}

\begin{abstract}
The present study comprises the measurement of total volatile organic compounds (TVOC) in ambient atmosphere of Delhi. The study has been carried out in three different ambient locations during winter and summer seasons of 2015. Real time monitoring was done for TVOC using a data-logging photo-ionization detector. The observed levels of TVOC were found to be higher during winter (ranged from 84.7 to $266.7 \mu \mathrm{g} / \mathrm{m}^{3}$ ) as compared to summer (ranged from 58.5 to $179.5 \mu \mathrm{g} / \mathrm{m}^{3}$ ) at all selected sites. The higher levels in winter could be due to low planetary boundary layer, calm condition and high atmospheric stability. These variations could be an account of factors such as distribution of emission sources around the sampling site and the prevailing meteorological conditions. It is clearly noticed that the levels of TVOC were found to be higher and lower during the morning and noon time. The higher levels of TVOC have been noticed during weekdays as compared to weekends at all the studied sites. It could be attributed to heavy traffic load, traffic flow and human activities during the weekdays. The association of TVOC with meteorological variables (ambient temperature and relative humidity) was also studied. Results showed that TVOC is positive weakly correlated with ambient temperature respectively during winter $\left(R^{2}=0.35\right)$ and summer $\left(R^{2}=0.10\right)$ seasons. On the other hand, relative humidity showed negative moderately strong correlation with observed levels of TVOC during winter $\left(R^{2}=0.66\right)$ and summer $\left(R^{2}=0.54\right)$.
\end{abstract}

Keywords: TVOC, Ambient temperature, Relative humidity, Compressed Natural Gas, Traffic density

\section{Introduction}

Air quality of an environment is considered to be of great concern due to its adverse impact on the human health nowadays. Recent phenomenon of industrialization, liberalization and commercialization in last few decades has resulted in the increase of concentration for various pollutants in the environment. Air quality is decided by the presence of quality and quantity of the pollutants in the atmosphere. Criteria air pollutants $\left(\mathrm{O}_{3}\right.$, $\mathrm{NO}_{2}, \mathrm{CO}, \mathrm{PM}_{2.5}, \mathrm{SO}_{2}$ and $\mathrm{Pb}$ ) along with volatile organic compounds are considered as major contributor. Among the harmful pollutants, VOCs are one of the most important category because of its environmental chemistry and impacts of human health. VOCs are a group of chemical compounds which include more than 200 compounds. When proper conditions and concentrations are available, the VOCs play important role in the atmospheric chemistry like formation/destruction of ozone in the troposphere, secondary organic aerosols formation and global warming (Alves et al. 2014; Cerón-Bretón et al. 2014; Choi et al. 2011; Filella and Peñuelas 2006; Kumar et al. 2014; Lewis et al. 2000; Ran et al. 2009; Rad et al. 2014).

In urban environment, the important anthropogenic sources of VOCs are burning of fossil fuel, vehicle exhaust and leakages from petroleum refineries (Sofuoglu et al. 2010). Along with anthropogenic sources, VOCs are also released by terrestrial plants (Peñuelas and Llusia 2001, 2003). The spread and occurrence of VOCs are highly dependent on the prevailing meteorological conditions viz. solar radiation, relative humidity, temperature and wind. VOCs are also important from the human health point of view because of its long and short term effects which may be non-carcinogenic and carcinogenic (Lee et al. 2002). Some of the VOCs are highly toxic and among them, some are known to be carcinogen (Civan et al. 2012). The non-carcinogenic effects are characterized by bodily irritation, asthma, hepato-toxic disorders and impairment in liver, kidneys, respiratory system and central nervous system (de Blas et al. 2012; Kumar et al. 2013). However, carcinogenic effects are characterized by lung, blood (leukemia and non-Hodgkin lymphoma), liver, kidney and biliary tract cancer (WHO 2000). The International Agency for Research on Cancer classified benzene as a potential carcinogenic type-I (IARC 2006; Paulo et al. 2010). It produces central nervous system toxicity and feto-toxicity (Fustinoni et al. 2000).

Extensive efforts have been made to determine and regulate the emissions of VOCs to protect public from exposure to these organic contaminants by the various regulatory bodies. The WHO and USEPA have established quantitative risk assessment in terms of cancer and non-cancer risks regarding VOCs (Ramirez et al.

\footnotetext{
*Dr. Deepak Singh, School of Environmental Sciences, Jawaharlal Nehru University, New Delhi, 110067, India Corresponding author email id: deepaksingh1947@gmail.com
} 
2012; WHO 2000; USEPA 1997). In India, due to the immense rise in the air pollution levels, Supreme Court of India (SCI) in 1998, ordered the state government to take necessary steps to improve the air quality by reducing vehicular pollution in capital city of Delhi. The directives of SCI have led the state government to move the public transport to compressed natural gas (CNG) has been implemented since year 2001. At present, capital city boasts of a complete CNG driven commercial bus fleet, three-wheelers (auto rickshaws), taxis, and rural transport vehicles (Singh et al. 2013). CNG fuel is clear liquid, odourless and non-corrosive and composed mainly consists of methane $\mathrm{CH}_{4}$ which is compressed to the pressure of 20-25 MPa in a cylinder. The unique topography, different types of land use pattern, prevailing meteorological conditions due to its location in tropics and large number of vehicles running on the fuels like CNG, petrol, diesel etc in capital city of Delhi, India, prompted us to carry out this study. In the recent decades, the city has seen a remarkable increase in the number of vehicles and at present it boast of the largest number of registered of vehicles i.e., 88.27 lakh (Transport Department, Delhi-2015). Therefore, the objective of the study is to assessment of spatio-temporal variability of TVOC at three representative sites varying in terms of land use pattern. Further, the differences in the levels of TVOC during weekdays and weekends at the selected sites have been evaluated. In addition to this, association observed levels of TVOC with meteorological parameters has also been examined.

\subsection{Sampling sites}

\section{Materials and methods}

The TVOC sampling was performed in Delhi, capital city of India which is situated at $28.61^{\circ} \mathrm{N}$ and $77.23^{\circ} \mathrm{E}$. It is spread over an area of $1483 \mathrm{~km}^{2}$ (51.90 and $48.48 \mathrm{~km}$ dimensions). It is situated at an altitude of $\sim 293 \mathrm{~m}$ above the sea level. Delhi has a sub-tropical climate consisting of well-defined four seasons i.e., summer, monsoon, autumn and winter. The summer season experiences windy conditions and temperature as high as $48^{\circ} \mathrm{C}$ whereas winter season is characterized by calm conditions and temperature as low as 3 to $4{ }^{\circ} \mathrm{C}$. Delhi receives most of its rain (average annual rainfall $714 \mathrm{~mm}$ ) during July to September from the southwesterly monsoonal winds and some rain during winters from north-westerly cold winds. In the present study, a total of three sites were selected: Bhikaji Cama Place (BK), Jawaharlal Nehru University (JN) and Rama Krishan Puram (RK). Of these sites BK, RK and JN was taken as representative site for the traffic intersection, residential and background, respectively. Figure 1 shows the map of Delhi having location of the selected sampling sites.

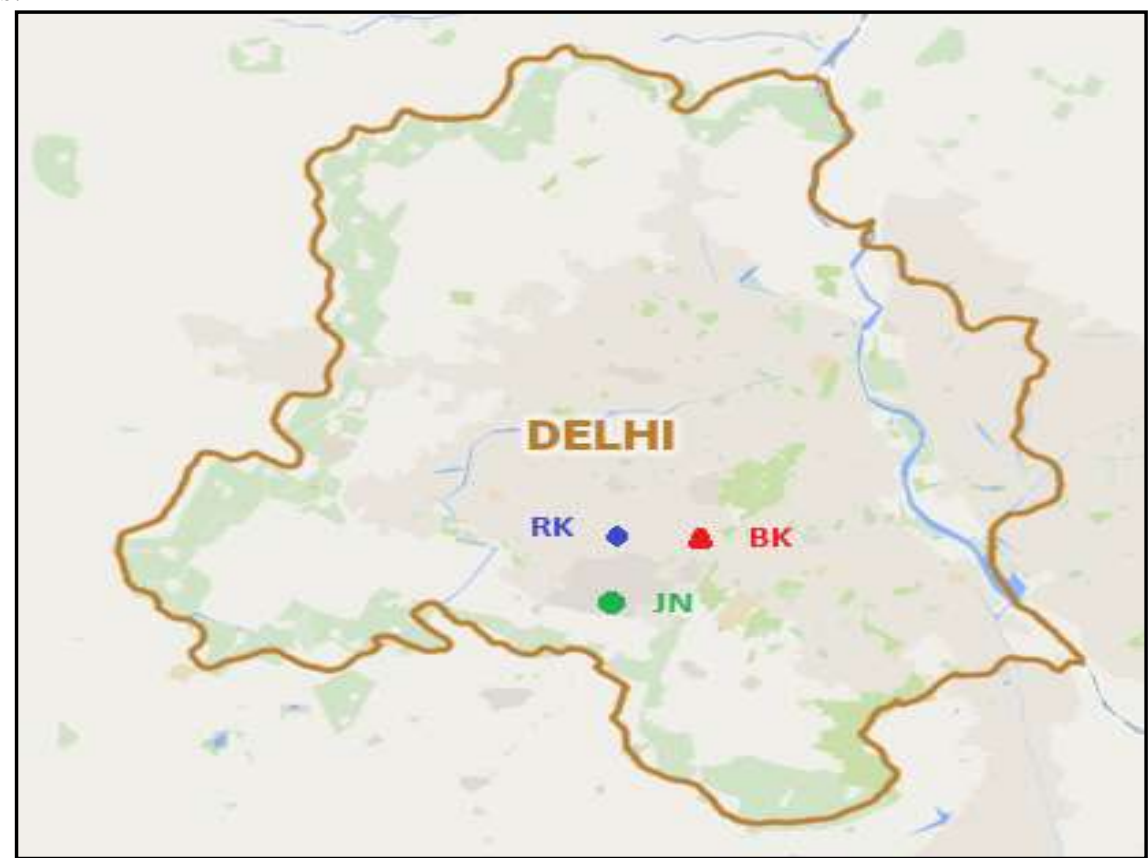

Fig. 1 Map of Delhi showing the three selected sampling sites (BK, JN and RK)

\subsection{Sample collection}

TVOC samples were collected during two seasons namely summer and winter at three sites in the year 2015. These two seasons represent extreme weather conditions in terms of meteorological parameters in Delhi, India. At each site, samples were collected during 8.00 am to 12.00 noon for four days during each season at each site. The four days were selected for sampling was distributed in such a way that the two days represent working day and next two days represent non-working days. Simultaneously, meteorological parameters were 
also monitored using Thermo-hygrometer for temperature and relative humidity. TVOC and meteorological parameters measurements were done at the height of $1.5 \mathrm{~m}$ (breathing zone) above the ground.

\subsection{TVOC measurement}

The real-time TVOC measurements were done using a portable, data-logging PhoCheck 5000 photoionization detector (PID) having 10.6-eV ultraviolet lamp technology (Ion Science Ltd, Cambridge, England). Here, TVOC comprise a large range of gases to characterize the pollutant load in terms of VOCs and a basis on which quality of air is assessed (Andersson et al. 1997). The instrument works on the principal that uses the ultraviolet (UV) light source to break down VOCs in the air into positive and negative ions. Then, the PID detects or measures the charge of the ionized gas, with the charge being a function of the concentration of VOCs in the air. The concentration is displayed in the monitor digital display. Over $220 \mathrm{ml} / \mathrm{min}$ of air was drawn through the PhoCheck's internal pump into the instrument and a 1-s measurement interval was set for the PID data logger. Calibration was performed by $100 \mathrm{ppm}$ isobutylene and zero air according to the manufacturer's instructions. The details of technical specifications of Ion Science PhoCheck 5000 TVOC monitor are listed in Table 1.

Table 1. Technical specification of Ion Science PhoCheck 5000 TVOC monitor

\begin{tabular}{|l|l|}
\hline Technical specification \\
\hline Detector & $10.6 \mathrm{eV}$ Krypton PID lamp \\
\hline Detection range & $1 \mathrm{ppb}-10000 \mathrm{ppm}$ \\
\hline Accuracy & $\pm 5 \%$ displayed reading \pm one digit \\
\hline Linearity & $\pm 5 \%$ \\
\hline Temperature & Operating: -20 to $60^{\circ} \mathrm{C},-4$ to $140{ }^{\circ} \mathrm{F}$ \\
\hline Humidity & Operating: $0-99 \% \mathrm{RH}$ (non-condensing) \\
\hline
\end{tabular}

\subsection{Seasonal variability of TVOC}

\section{Results and Discussions}

Figure 2 clearly explains the variability of TVOC in the ambient air of three different locations during the two seasons. The box whisker plot shows the five different statistical parameters (min, max, median, lower and upper quartile) of observed TVOC levels during the targeted seasons. TVOC showed the higher values at all the sites during winter as compared to summer. The mean values of TVOC are found to be $211.6 \mu \mathrm{g} / \mathrm{m}^{3}$ (ranged from 123.7 to $266.7 \mu \mathrm{g} / \mathrm{m}^{3}$ ), $141.1 \mu \mathrm{g} / \mathrm{m}^{3}$ (ranged from 84.7 to $173.2 \mu \mathrm{g} / \mathrm{m}^{3}$ ) and $156.8 \mu \mathrm{g} / \mathrm{m}^{3}$ (ranged from 94.7 to $207.5 \mu \mathrm{g} / \mathrm{m}^{3}$ ) for BK, JN and RK, respectively. On the other hand, summer experienced the TVOC as 144.1 $\mu \mathrm{g} / \mathrm{m}^{3}$ (ranged from 99.2 to $179.5 \mu \mathrm{g} / \mathrm{m}^{3}$ ), $103.3 \mu \mathrm{g} / \mathrm{m}^{3}$ (ranged from 58.5 to $126.2 \mu \mathrm{g} / \mathrm{m}^{3}$ ) and $99.9 \mu \mathrm{g} / \mathrm{m}^{3}$ (ranged from 67.6 to $129.2 \mu \mathrm{g} / \mathrm{m}^{3}$ ) for BK, JN and RK, respectively. These variations could be an account of factors such as distribution of emission sources around the sampling site and the prevailing meteorological conditions. The source emission strength variations, meteorological conditions and seasonal variability of $\mathrm{OH}$ radicals play an important role in the seasonal variation of VOCs in the troposphere. The calm conditions with low temperature, high relative humidity, low wind speed and low planetary boundary layer could be the main reason for the higher levels of TVOC during winter. On the other hand, high mixing height, maximum dispersion and degradation of VOCs due to $\mathrm{OH}$ radicals cause the lower levels during summer. Higher temperature and solar radiation in the summer is associated with high losses of VOCs by photochemical degradation (Lai et al., 2013). A possible reason for the variability of levels of aromatic VOCs are mainly traffic, evaporative emissions, fuel combustion and use of solvents and gasoline spills (Na et al. 2005). Similar results have been reported in studies performed in the different cities across the world, i.e. Dunkerque (Roukos et al. 2009) and Tokyo (Shirai et al. 2007).

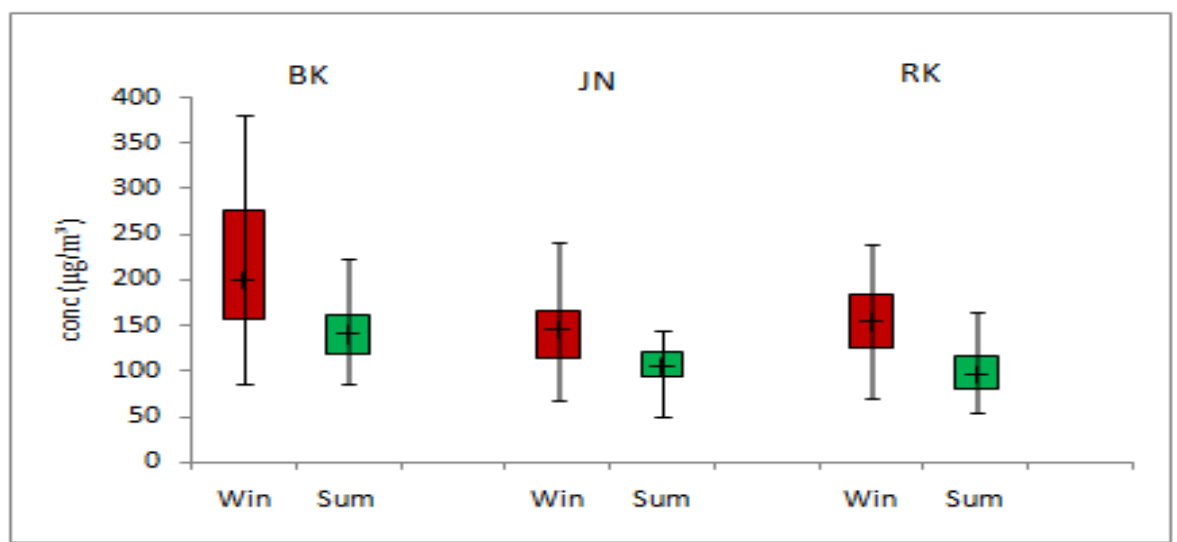

Fig. 2 Seasonal (summer and winter) variability of TVOC at the three selected sites 


\subsection{Trend analysis of TVOC during observation}

Figure 3 and 4 showed the trend of TVOC in the ambient air of three different locations namely BK, JN and RK during winter and summer, respectively. It is clearly observed that the more or less similar trend of TVOC at the three locations with different magnitudes. The concentrations showed increasing trend in the morning and attained peak values during 10-11 am, then starts decreasing till noon. The variability could be due to traffic flow, traffic volume and meteorological variables throughout the studied period. The accumulation of air pollutants in the morning could be explained by the presence of calm meteorological conditions. However, the elevation of planetary boundary layer (PBL) during daytime enhanced the dispersion and dilution of the pollutants (Zhang et al. 2012). Along with it, photochemical destruction could also be the reason for the lower levels of VOCs during noon (Tan et al. 2012).

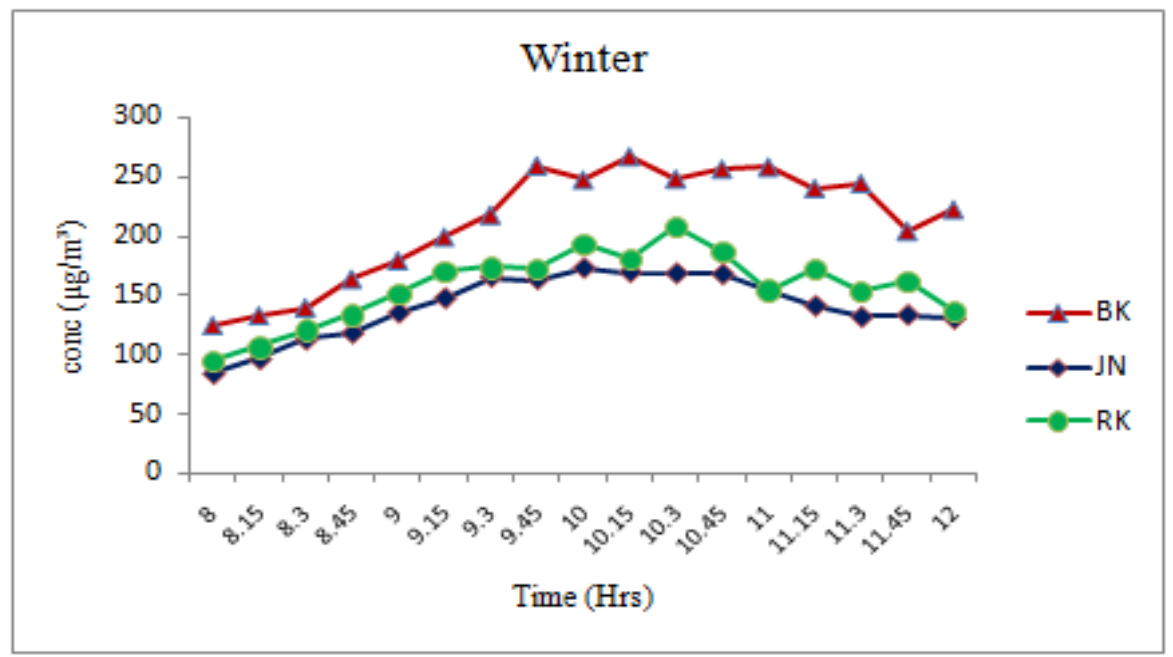

Fig. 3 Pattern of mean TVOC throughout the sampling duration in winter at three sites

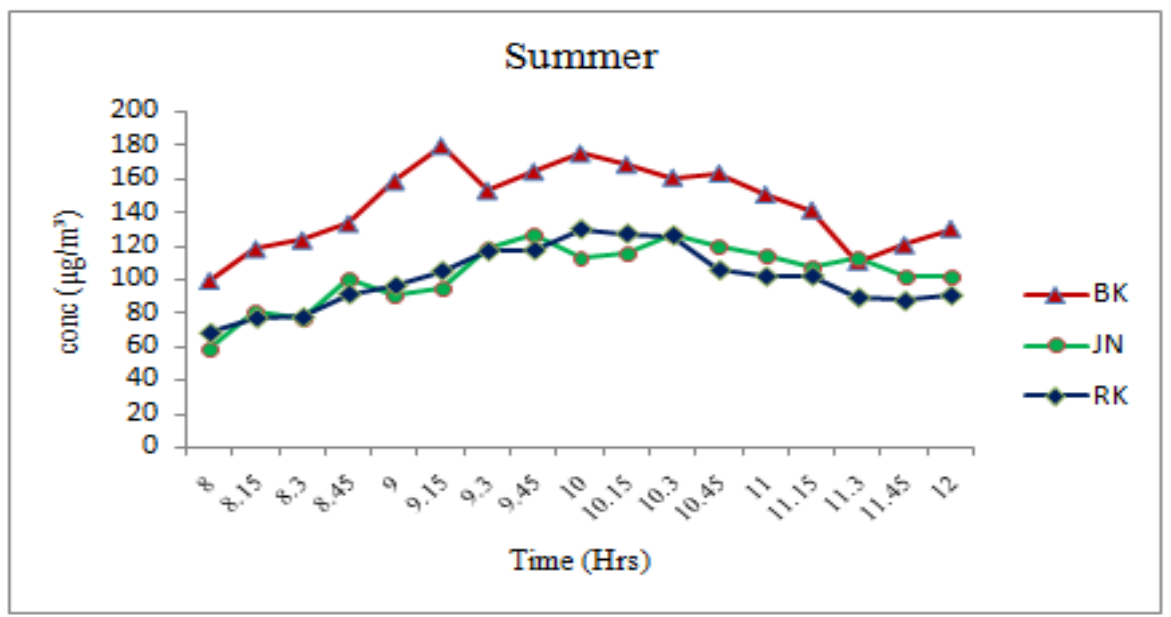

Fig. 4 Pattern of mean TVOC throughout the sampling duration in summer at three sites

\subsection{Weekdays and weekends TVOC comparison}

\subsubsection{Seasonal variability}

To see the any insight difference during the weekdays (WD) and weekends (WE) levels, the separate analysis has been performed. The results of difference between weekdays and weekends can provide some insight into the effect of vehicular traffic on the measured VOC concentrations. A clear difference has been noticed in the levels of TVOC during weekdays and weekends. It could be attributed due to heavy traffic load and human activities during the weekdays. The weekdays were found to be more polluted with TVOC as compared weekends at all the sites. The TVOC values were found to be more during the winter as compared to the summer. During winter, the levels of TVOC experienced as 262.9/166.1/184.8 and 160.4/116.1/128.7 for BK/JN/RK during weekdays and weekends, respectively (Figure 5). However, the TVOC levels of summer were found to be 161.4/113.4/118.9 and 126.8/93.2/81.1 for BK/JN/RK during weekdays and weekends, respectively (Figure 6). 


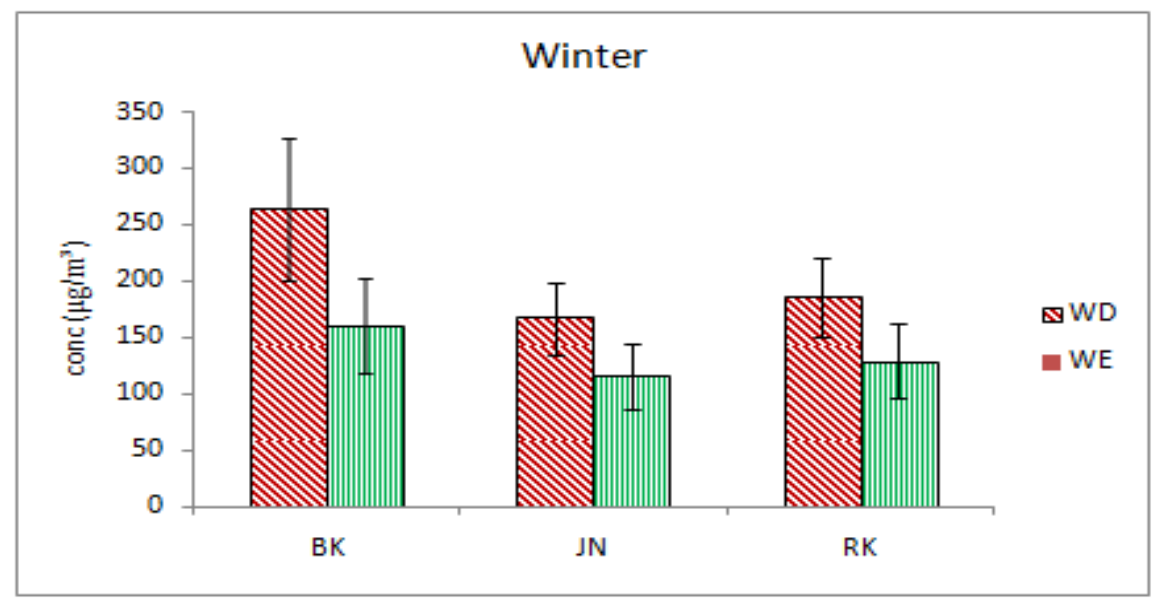

Fig. 5 Variability of TVOC during weekdays and weekends in winter at three sites

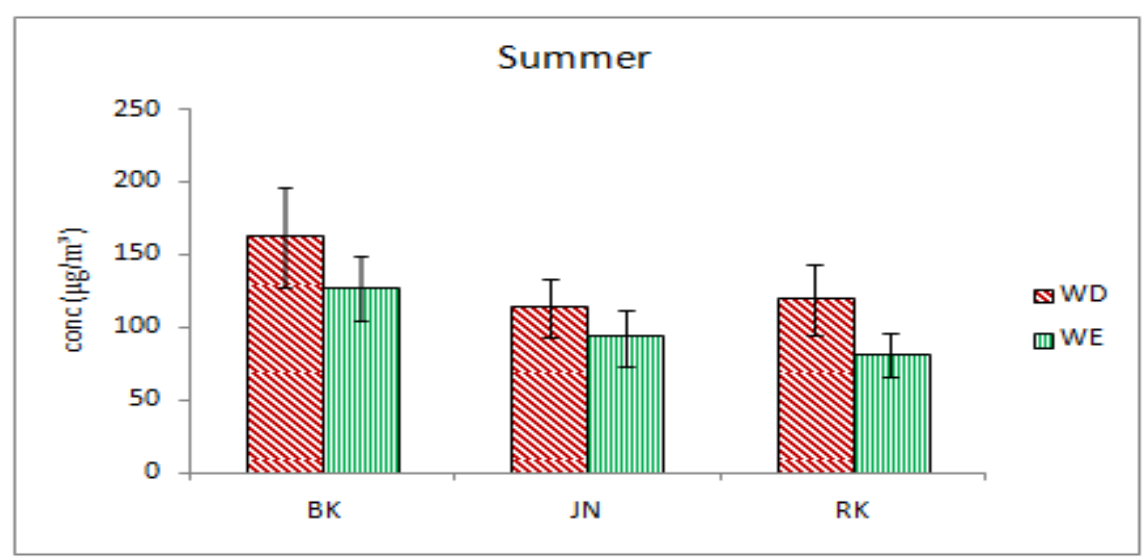

Fig. 6 Variability of TVOC during weekdays and weekends in summer at three sites

\subsubsection{Trend analysis of TVOC during weekdays and weekends}

In this section, the trend analysis has been carried out for the selected three locations during weekdays and weekends of both winter and summer seasons. Figure 7 (a-c) and 8 (a-c) depict the trend analysis during weekdays and weekends of winter and summer, respectively. It is clearly noticed from the figures that the lower concentrations are observed during weekends in contrast to weekdays in the both seasons. The TVOC concentration on both weekdays and weekends were found to be more at BK followed by RK and JN (BK > RK $>\mathrm{JN}$ ). The higher concentration at BK is due to the higher vehicular density as compare to other two sites. Also from the figure, it can be seen that the weekdays have more concentration as compared to the weekends which is due to the less number of commuters due to the weekend holidays.

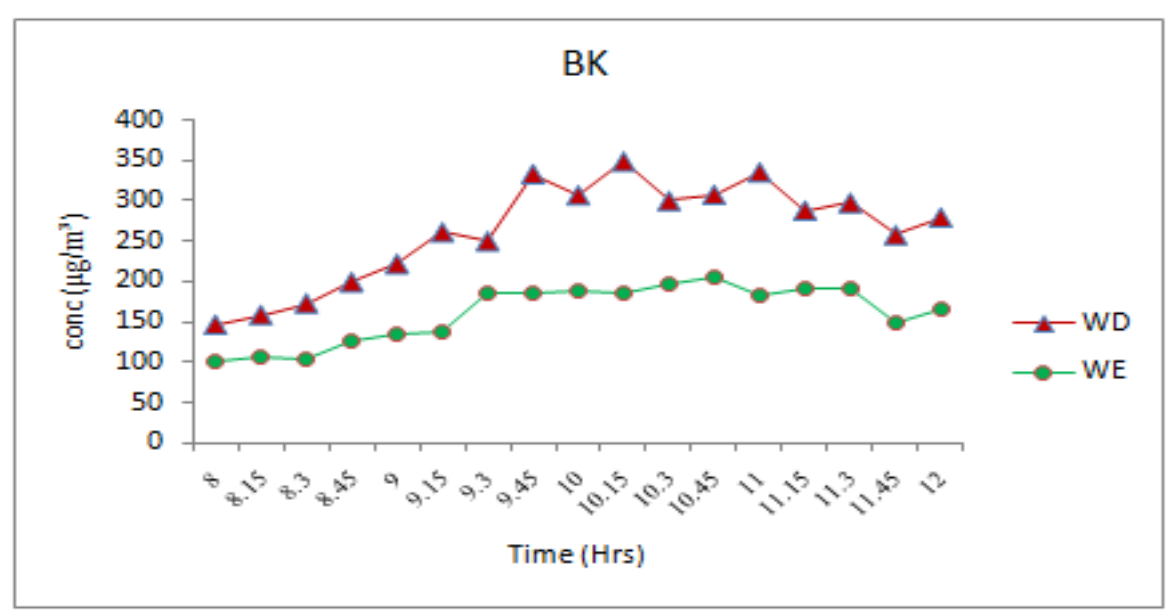

Fig. 7 (a) Pattern of mean TVOC during weekdays and weekends at BK in winter 


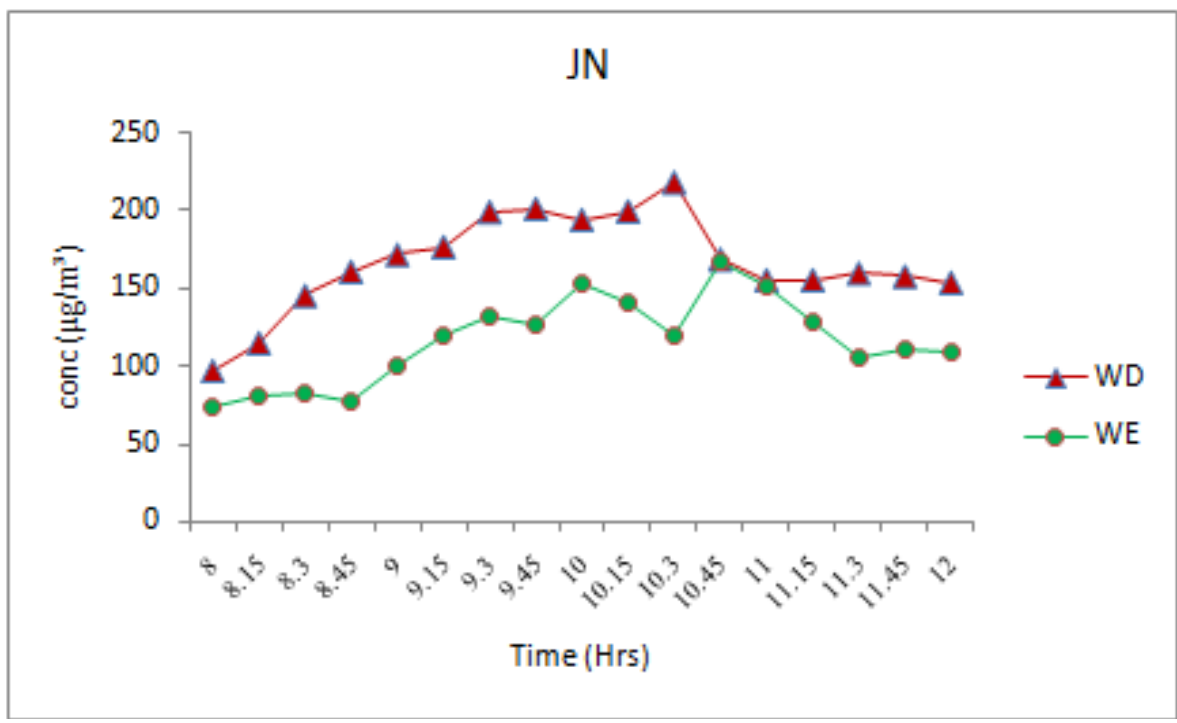

Fig. 7 (b) Pattern of mean TVOC during weekdays and weekends at JN in winter

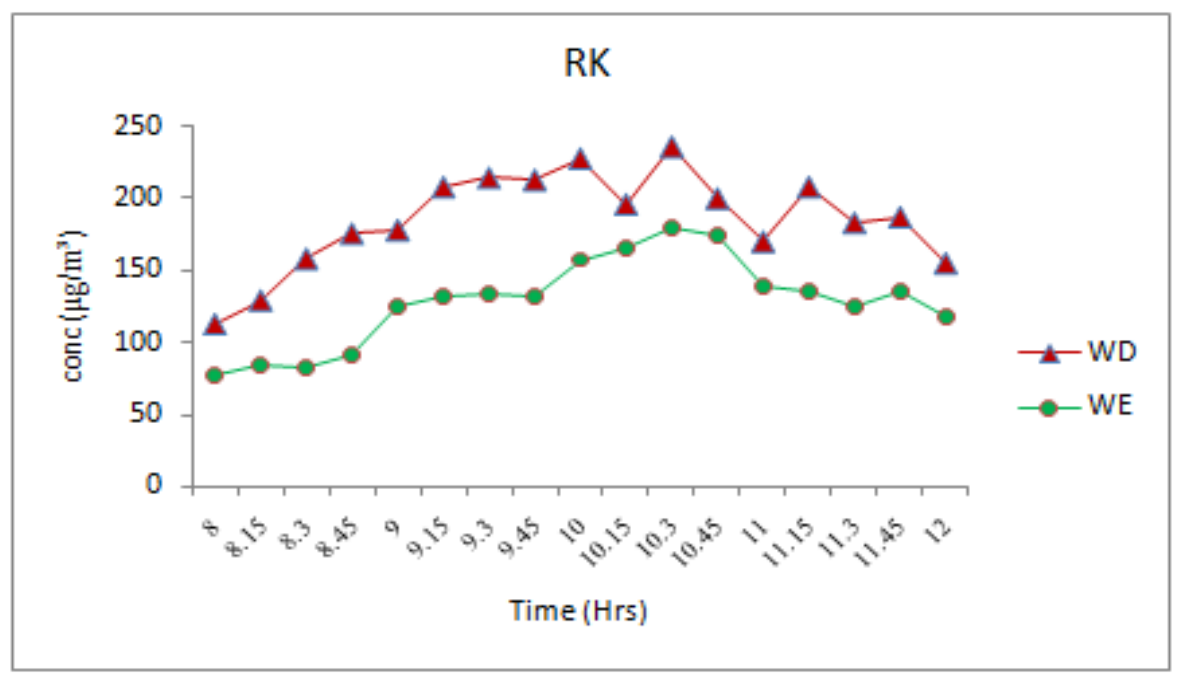

Fig. 7 (c) Pattern of mean TVOC during weekdays and weekends at RK in winter

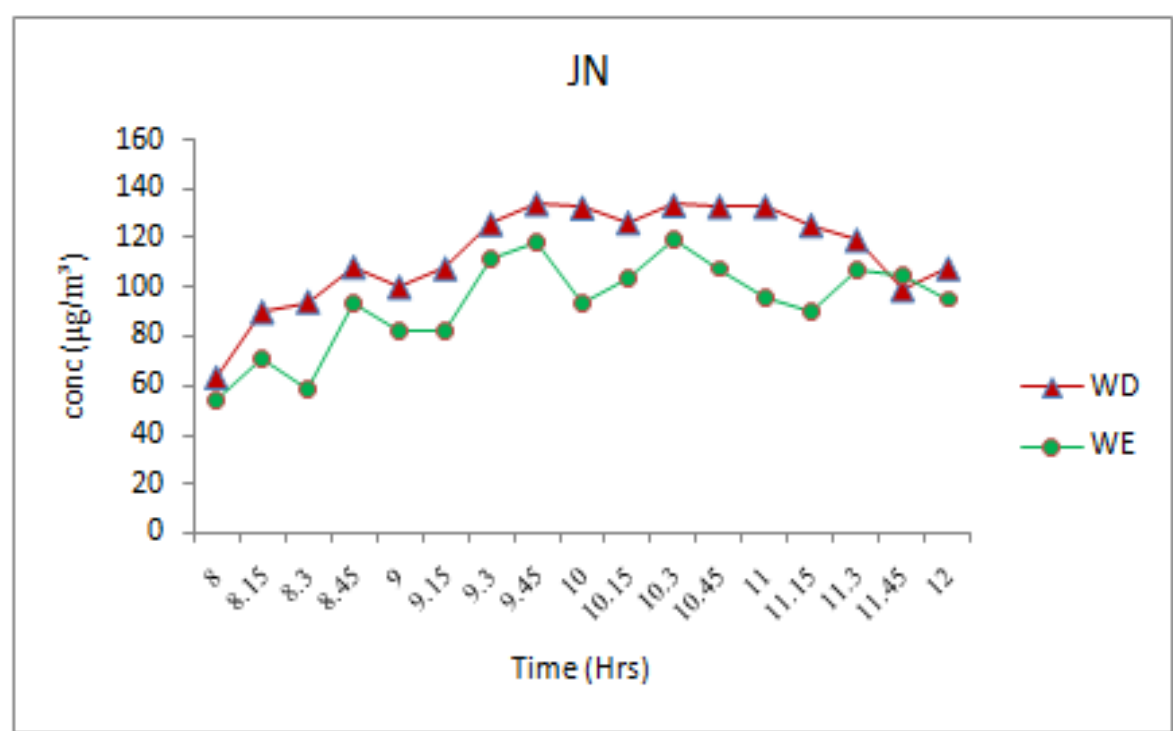

Fig. 8 (a) Pattern of mean TVOC during weekdays and weekends at BK in summer 


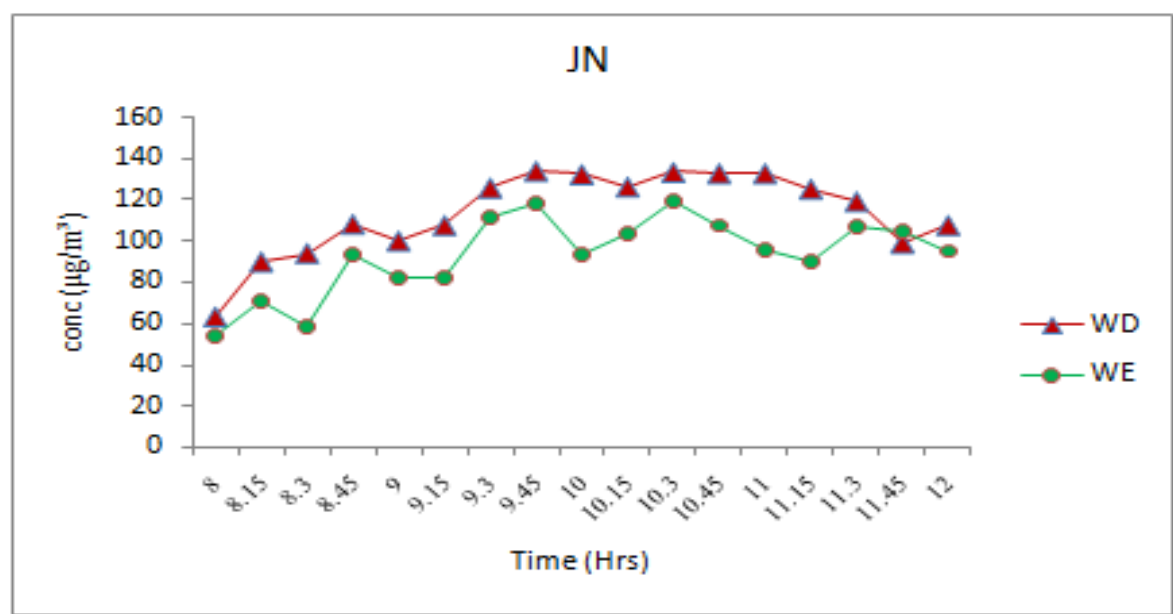

Fig. 8 (b) Pattern of mean TVOC during weekdays and weekends at JN in summer

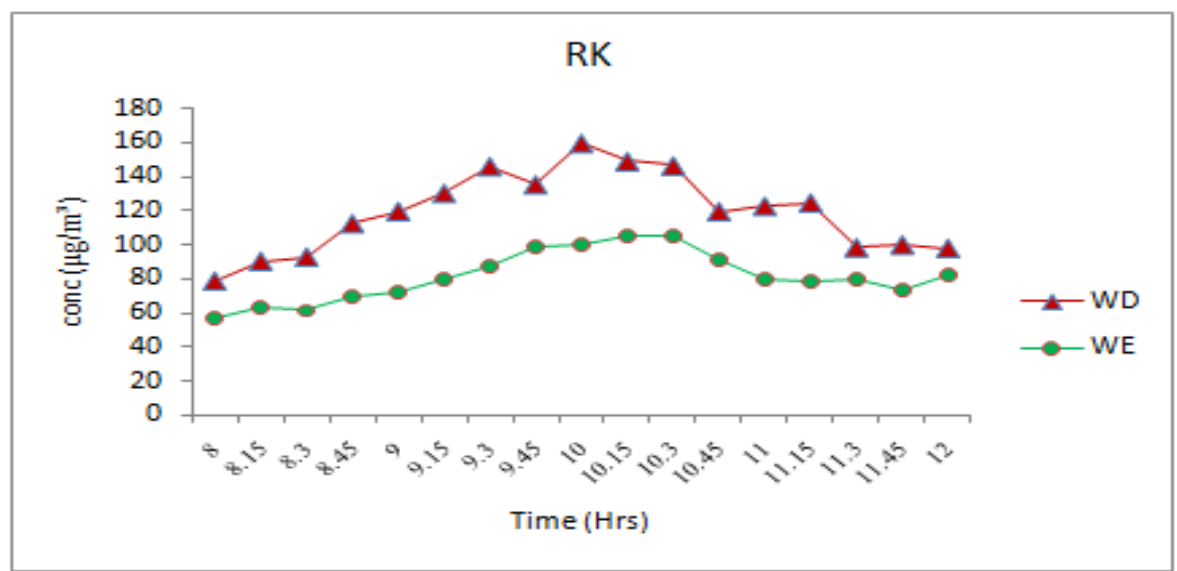

Fig. 8 (c) Pattern of mean TVOC during weekdays and weekends at RK in summer

\subsection{Relationship with the Meteorological parameters (temperature and relative humidity)}

In this section, the relationship between observed levels of TVOC with ambient temperature and relative humidity has been analysed during both seasons. Figure 9 and 10 illustrate the association of TVOC with ambient temperature and relative humidity, respectively for two seasons. It can be inferred that TVOC is positive weakly correlated with ambient temperature respectively during winter $\left(R^{2}=0.35\right)$ and summer $\left(\mathrm{R}^{2}=0.10\right)$ seasons. On the other hand, relative humidity showed negative moderately strong correlation with observed levels of TVOC during winter $\left(\mathrm{R}^{2}=0.66\right)$ and summer $\left(\mathrm{R}^{2}=0.54\right)$.

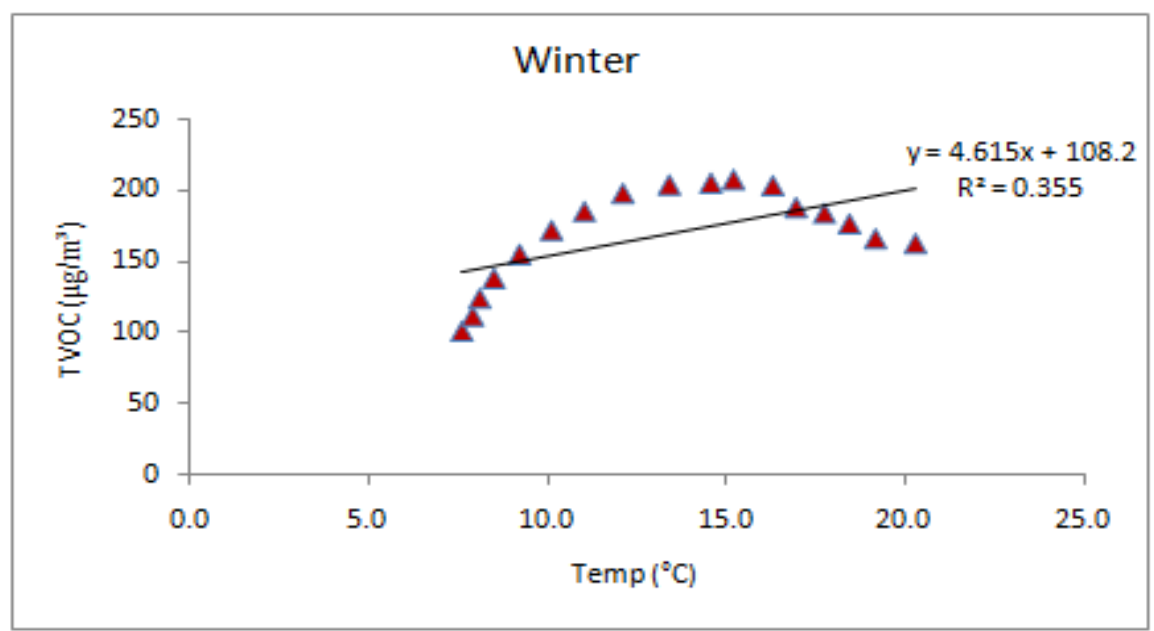

Fig. 9 (a) Relationship of TVOC with ambient temperature during winter 


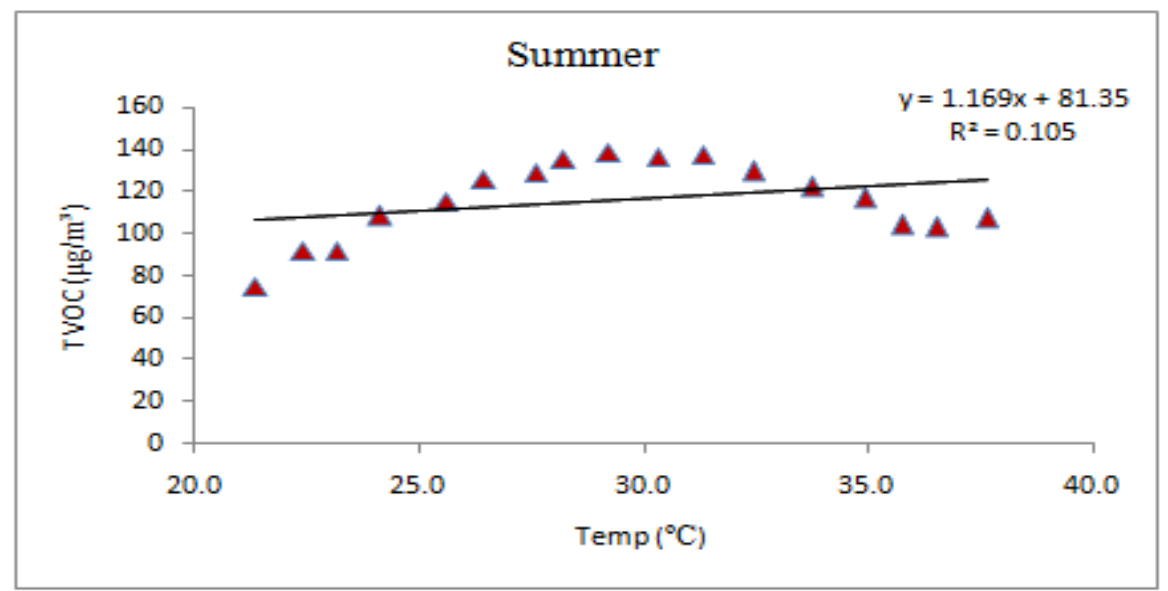

Fig. 9 (b) Relationship of TVOC with ambient temperature during summer

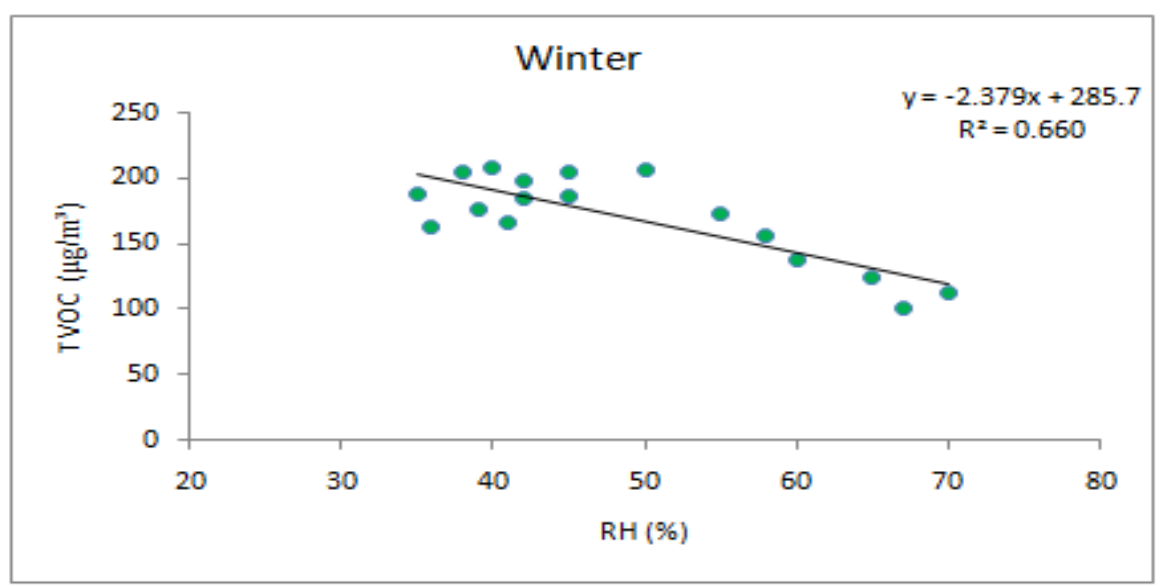

Fig. 10 (a) Relationship of TVOC with relative humidity during winter

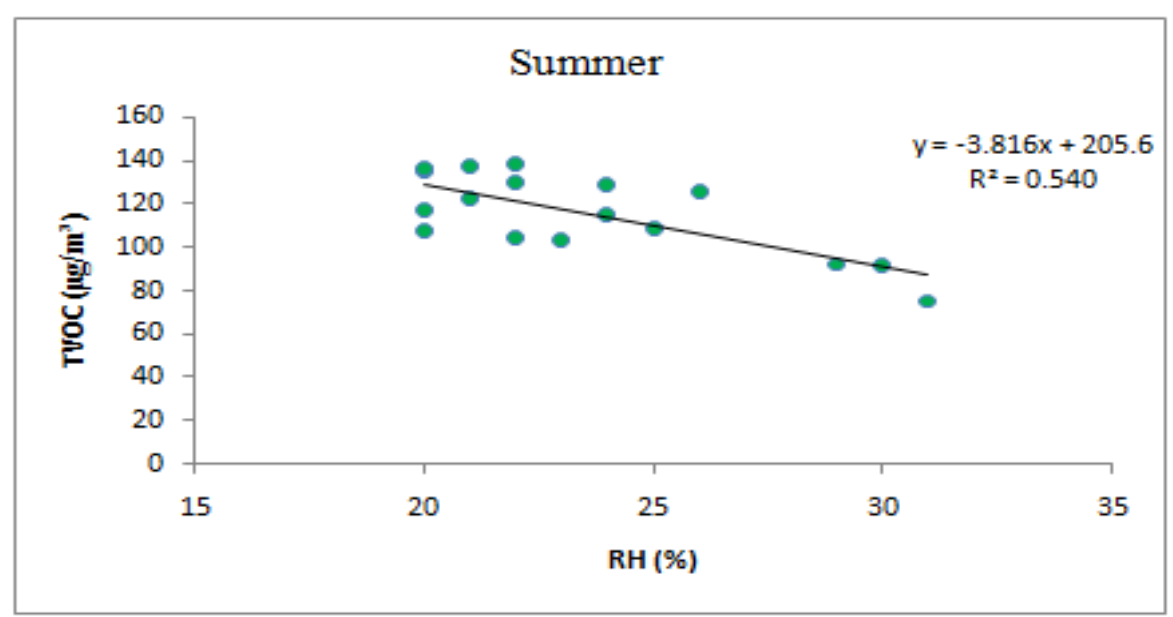

Fig. 10 (b) Relationship of TVOC with relative humidity during summer

\section{Conclusions}

After the CNG implementation in the transport sector in Delhi many changes have been found by the scientists in the concentration of the air pollutants in the environment. One of them is VOCs are one of the important pollutants which have significant role in atmospheric chemistry and impacts on human health. The present study attempts to find out the spatio-temporal variability of TVOC at three ambient locations in Delhi. Along with spatio-temporal analysis, the study also tries to find the differences in the TVOC during weekdays and weekends. In addition to this, how the meteorological variables influence the concentration of TVOC is also evaluated. Results showed that the level of TVOC is observed to be higher in winter as compared to summer 
due to high atmospheric stability at all the selected sites. The levels of TVOC found to be increasing from the morning hours and attained peak around 10 to 11 am and again decreased in the noon time. The weekdays levels of TVOC have witnessed with higher concentrations in contrast to weekends which was related to the vehicular density. On examining the relationship with meteorological parameters, temperature and relative humidity showed positive weak and negative moderately strong correlation respectively with the observed levels of TVOC. The most of the sources of TVOCs in Delhi were found to be the vehicular exhaust coming from vehicles running on petrol, diesel and CNG of which of CNG driven vehicles have significant role in the emission of VOCs in the urban environment of Delhi.

\section{Acknowledgement}

The research work was supported by the CSIR, New Delhi and is part of the project sanctioned under the Pool Scientist Scheme.

\section{References}

[1]. Alves CA, Evtyugina M, Cerqueira M, Nunes T, Duarte M, Vicente E. (2014) Volatile organic compounds emitted by the stacks of restaurants. Air Qual. Atmos. Health. doi:10.1007/s11869-014-0310-7

[2]. Andersson K, Bakke JV, Bjorseth O, Bornehag CG, Clausen G, Hongslo JK, Kjellman M, Kjergaard S, Levy F, Molhave L, Skerfving S, Sundell J. (1997) TVOC and health in non-industrial indoor environments. Indoor Air 7:78-91.

[3]. Cerón BJG, Cerón BRM, Kahl JDW, Ramírez LE, Guarnaccia CC, Aguilar UA, Montalvo RC, Anguebes FF, López CU. (2014) Diurnal and seasonal variation of BTEX in the air of Monterrey, Mexico: preliminary study of sources and photochemical ozone pollution. Air Qual. Atmos. Health. doi:10.1007/s11869-014-0296-1.

[4]. Choi SW, Sang-Won P, Chang-Seop L, Hye-Jin K, Sunyoung B, Hilary II. (2009) Patterns of VOC and BTEX concentration in ambient air around industrial sources in Daegu, Korea. J Environ Sci Health 44:99-107.

[5]. Civan MY, Kuntasal ÖO, \& Tuncel G. (2012). Contribution of VOCs to Ozone Formation in Bursa Atmosphere, 2(1), 34-40

[6]. Fustinoni S, Buratti M, Giampiccolo R, Brambilla G, Foà V, Colombi A. (2000) Comparison between blood and urinary toluene as biomarkers of exposure to toluene. Int Arch Occup. Environ. Health 73(6):3 89-396

[7]. IARC. IARC Monographs on the evaluation of carcinogenic risks to humans. Complete list of agents evaluated and their classification; IARC, (2006).

[8]. Kumar A, Singh BP, Punia M, Singh D, Kumar K, Jain VK. (2014) Determination of volatile organic compounds and associated health risk assessment in residential homes and hostels within an academic institute, New Delhi. Indoor Air, 24, 474-483.

[9]. Kumar A, Singh BP, Punia M, Singh D, Kumar K, Jain VK. (2013) Assessment of indoor air concentrations of VOCs and their associated health risks in the library of Jawaharlal Nehru University, New Delhi. Environ. Sci. Pollut. Res. 21:2240-2248.

[10]. Lai C, Chuang K, \& Chang J. (2013) Source Apportionment of Volatile Organic Compounds at an International Airport, Aerosol Air Qual. Res. 689-698.

[11]. Lee SC, Chiu MY, Ho KF, Zou SC, Wang X. (2002) Volatile organic compounds (VOCs) in urban atmosphere of Hong Kong. Chemosphere 48:375-82.

[12]. Lewis AC, Carslaw N, Marriott PJ, Kinghorn RM, Morrison P, Lee AL, Bartle KD, Pilling MJ. (2000) A larger pool of ozoneforming carbon compounds in urban atmospheres. Nature 405:778-781.

[13]. Peñuelas J \& Llusià J. (2003) BVOCs: plant defense against climate warming? Trends Plant Sci 8:105-109.

[14]. Rad HD, Babaei AA, Goudarzi G, Angali KA, Ramezani Z, Mohammadi MM. (2014) Concentrations and sources of BTEX in ambient air of Ahvaz metropolitan city. Air Qual. Atmos. Health 7:515-524.

[15]. Ramírez N, Cuadras A, Rovira E, Borrull F \& Maria R. (2012) Chronic risk assessment of exposure to volatile organic compounds in the atmosphere near the largest Mediterranean industrial site. Environ. Intl. 39(1), 200-209.

[16]. Ran L, Zhao C, Geng F, Tie X, Tang X, Peng L. Guenther A. (2009) Ozone photochemical production in urban Shanghai, China: Analysis based on ground level observations, J Geophy. Res. 114, 1-14.

[17]. Roukos J, Locoge N, \& Plaisance H. (2009) VOC in an urban and industrial harbor on the French North Sea coast during two contrasted meteorological situations, Environ Poll. 157, 3001-3009.

[18]. Shirai T, Yokouchi Y, Blake DR, Kita K, Izumi K, Koike M, ... Kondo Y. (2007) Seasonal variations of atmospheric $\mathrm{C}_{2}-\mathrm{C}_{7}$ nonmethane hydrocarbons in Tokyo, J Geophy. Res. 112(x), 1-18.

[19]. Singh D, Prakash A, Srivastava AK, Kumar K, Jain VK. (2013) The effects of meteorological parameters in ambient noise modelling studies in Delhi. Environ. Monit. Assess. 185, 1873-1882.

[20]. Sofuoglu SC, Aslan G, Inal F, Sofuoglu A. (2010) An assessment of indoor air concentrations and health risks of volatile organic compounds in three primary schools. Intl. J Hyg. Environ. Health 214:36- 46.

[21]. Tan J, Guo S, Ma Y, Yang F, He K, Yu Y, Chen G. (2012) Non-methane hydrocarbons and their ozone formation potentials in Foshan, China, Aerosol Air Qual. Res, 387-398.

[22]. Transport Department, Govt. of NCT, Delhi (2015)

[23]. USEPA (1998) Integrated Risk Information System (IRIS). Available at: www.epa.gov. US Environmental Protection Agency, Washington,DC, 1998 .

[24]. WHO (2000) Guidelines for Air Quality. World Health Organization Geneva, $190 \mathrm{pp}$

[25]. Zhang Y, Mu Y, Liu J, \& Mellouki A. (2012) Levels, sources and health risks of carbonyls and BTEX in the ambient air of Beijing, China. J of Environ. Sci, 24(1), 124-130. 